\title{
Management of raised intracranial pressure in aneurysmal subarachnoid hemorrhage: time for a consensus?
}

\author{
Naif M. Alotaibi, MD, ${ }^{1-3}$ Justin Z. Wang, MD, ${ }^{2}$ Christopher R. Pasarikovski, MD, ${ }^{2}$ \\ Daipayan Guha, MD, ${ }^{1,2}$ Fawaz AI-Mufti, MD, ${ }^{4}$ Muhammad Mamdani, PharmD, MPH, MA, ${ }^{5}$ \\ Gustavo Saposnik, MD, MSc, ${ }^{6,7}$ Tom A. Schweizer, PhD, ${ }^{1,2,6}$ and R. Loch Macdonald, MD, PhD1,2,6 \\ ${ }^{1}$ Institute of Medical Science, Faculty of Medicine, University of Toronto, and 'Division of Neurosurgery, Department of Surgery, \\ St Michael's Hospital, University of Toronto, Ontario, Canada; ' ${ }^{3}$ Department of Neurosurgery, National Neuroscience Institute, \\ King Fahad Medical City, Riyadh, Saudi Arabia; ${ }^{4}$ Department of Neurology and Critical Care, Robert Wood Johnson University \\ Hospital, New Brunswick, New Jersey; and ${ }^{5} \mathrm{Li}$ Ka Shing Centre for Healthcare Analytics Research and Training, Institute for \\ Clinical Evaluative Sciences; ${ }^{6}$ Neuroscience Research Program, Keenan Research Centre of the Li Ka Shing Knowledge \\ Institute of St. Michael's Hospital; and 'Stroke Outcomes and Decision Neuroscience Research Unit, St. Michael's Hospital, \\ University of Toronto, Ontario, Canada
}

\begin{abstract}
Elevated intracranial pressure (ICP) is a well-recognized phenomenon in aneurysmal subarachnoid hemorrhage (aSAH) that has been demonstrated to lead to poor outcomes. Despite significant advances in clinical research into aSAH, there are no consensus guidelines devoted specifically to the management of elevated ICP in the setting of aSAH. To treat high ICP in aSAH, most centers extrapolate their treatment algorithms from studies and published guidelines for traumatic brain injury. Herein, the authors review the current management strategies for treating raised ICP within the aSAH population, emphasize key differences from the traumatic brain injury population, and highlight potential directions for future research in this controversial topic.

https://thejns.org/doi/abs/10.3171/2017.7.FOCUS17426
\end{abstract}

KEY WORDS aneurysm; subarachnoid hemorrhage; aSAH; intracranial pressure; ICP; management

$\mathrm{N}$ EUROCRITICAL care of patients with aneurysmal subarachnoid hemorrhage (aSAH) requires collaborative efforts from multiple disciplines that treat and manage the consequences of both the primary hemorrhage and the secondary brain injury that may occur following rupture. ${ }^{2,66}$ Elevated intracranial pressure (ICP) has been recognized as a consequence of aSAH that may contribute to a patient's clinical decline. Despite significant advances in aSAH clinical research, there are no consensus guidelines devoted specifically to the management of elevated ICP in the setting of aSAH. Most centers therefore extrapolate their treatment algorithms from studies and published guidelines for traumatic brain injury (TBI), a strategy that may produce suboptimal outcomes as it fails to consider the differences in pathophysiology between the 2 entities., ${ }^{1,18}$ Herein, we review the current management strategies to treat raised ICP in the aSAH population, highlight key differences from the TBI population, and identify high-yield areas for future study in this controversial topic.

\section{Raised ICP in aSAH \\ Prevalence and Etiologies}

Elevated ICP (as defined in TBI as $>20 \mathrm{~mm} \mathrm{Hg}$ ) is common in aSAH and can occur in an acute (within 24 hours), subacute (up to 7-10 days), and delayed (after 10 days) fashion following hemorrhage. ${ }^{35,50}$ In addition, elevated ICP may worsen other aSAH-related complications and overall prognosis. ${ }^{50}$ The extended time of risk

ABBREVIATIONS aSAH = aneurysmal subarachnoid hemorrhage; CPP cerebral perfusion pressure; CSF = cerebrospinal fluid; DCI = delayed cerebral ischemia; EVD external ventricular drain; ICH = intracerebral hemorrhage; ICP = intracranial pressure; IVH = intraventricular hemorrhage; RCT = randomized controlled trial; TBI = traumatic brain injury.

SUBMITTED June 27, 2017. ACCEPTED July 31, 2017.

INCLUDE WHEN CITING DOI: 10.3171/2017.7.FOCUS17426. 
and multifactorial contributors associated with elevated ICP following aSAH make it unique when compared with other causative pathologies associated with intracranial hypertension such as TBI or ischemic stroke.

It has been estimated that more than $50 \%$ of aSAH patients will have an ICP $>20 \mathrm{~mm} \mathrm{Hg}$ at some point during their hospital stay. ${ }^{34}$ This percentage is even higher among aSAH patients who present in poor clinical status $(60 \%-70 \%) .{ }^{34}$ Although these numbers are still commonly quoted and have been reported in previous reviews, ${ }^{50,51}$ it should be noted that they were initially obtained from a retrospective case series of aSAH patients who underwent craniotomy following aneurysm rupture.$^{34} \mathrm{In}$ this series of 433 patients, all aSAH patients underwent postoperative ICP monitoring but only $33 \%$ were monitored preoperatively. A recent prospective study, however, showed similarly high rates of elevated ICP following aSAH. Zoerle et $\mathrm{al}^{74}$ recorded episodes of ICP $>20 \mathrm{~mm} \mathrm{Hg}$ lasting at least 5 minutes and the mean ICP value during every 12-hour interval in 116 patients with aSAH. More than $80 \%$ of patients had at least one episode of elevated ICP, and $36 \%$ of those patients had a mean ICP $>20 \mathrm{~mm} \mathrm{Hg}$ during their hospital stay.

The most common cause of elevated ICP in aSAH is hydrocephalus-either communicating hydrocephalus, due to impaired cerebrospinal fluid (CSF) absorption from arachnoid villi/granulations as a result of blood in the subarachnoid space, or obstructive hydrocephalus, due to direct blockage of CSF pathways via intraventricular hemorrhage (IVH), which is seen in up to $50 \%$ of aSAH cases. ${ }^{50}$ The second most common cause is intracerebral hemorrhage (ICH), which occurs in approximately $30 \%$ of patients. ${ }^{22} \mathrm{ICH}$ and IVH are most frequently seen after initial rupture, but they can occur during rebleeding or as intra- or postoperative complications during aneurysm securing procedures.

Another common cause of raised ICP in aSAH is global cerebral edema, which is diagnosed on CT scans based on effacement of the hemispheric sulci and basal cisterns, with loss of hemispheric gray-white matter differentiation. ${ }^{13}$ It can be seen on initial CT scans after aneurysm rupture in $8 \%$ of patients but may also be found in delayed fashion in $10 \%-12 \%$ of patients. ${ }^{13}$ The pathophysiology of global cerebral edema is complex and the postulated mechanisms involved include intracranial circulatory arrest and sudden increase in ICP. ${ }^{53}$

Severe refractory vasospasm is not uncommon following aSAH and may require aggressive treatment with intraarterial vasodilator therapy using nicardipine, papaverine, milrinone, verapamil, or a combination of those. ${ }^{21}$ High ICP in aSAH can occur following vasodilator therapy, especially with papaverine. ${ }^{16}$ The mechanism of this complication is not well understood, but a sudden increase in cerebral blood volume secondary to vasodilation is probably the cause. ${ }^{16}$ A multicenter randomized study (ClinicalTrials.gov identifier NCT01996436) is currently being conducted to compare different intraarterial agents, which is expected to provide a higher level of evidence on the effect of these medications on ICP in the aSAH population.

Other less common causes of elevated ICP in aSAH include subdural hematoma (5\%), massive cerebral infarction secondary to vasospasm (2\%-3\%), and extracranial causes such as raised intrathoracic pressure from neurogenic pulmonary edema, central fever, severe hyponatremia, or overcorrection of hypernatremia. ${ }^{47,58,70,72}$

\section{Monitoring Strategies}

Patients with good neurological status who are responsive to instruction are usually monitored through serial clinical examinations. Since the majority of patients with aSAH either present with hydrocephalus or develop it at some point during their hospital stay, external ventricular drains (EVDs) are most commonly used both to monitor and manage elevated ICP via CSF drainage if needed. ${ }^{18}$ It is for the latter reason that parenchymal pressure monitors are rarely used in aSAH as they do not allow therapeutic CSF drainage.$^{66}$ EVDs can also assist in determining if there is a need for permanent CSF diversion such as via insertion of a ventriculoperitoneal shunt. ${ }^{27}$ The main disadvantage of using EVDs for ICP monitoring is that ICP values are unreliable when the EVD is open and CSF is being continuously drained. EVDs must be closed for several minutes to accurately assess the true ICP value. ${ }^{61}$

The use of other invasive monitoring, such as microdialysis, tissue oxygenation probes, and radioactive tracers, to predict secondary ischemia/hypoxia in aSAH has not yet gained broad clinical acceptance, and the current evidence is insufficient to support its routine use. ${ }^{66}$ Similarly, noninvasive methods of ICP monitoring, including near-infrared spectroscopy, optic nerve sheath diameter monitoring, pulsatility index on transcranial Doppler ultrasonography, and electroencephalogram power spectrum analysis, are evolving technologies that have tremendous potential but currently remain in the experimental phase..$^{11,73}$

In 2014, researchers and clinical experts from the Neurocritical Care Society and the European Society of Intensive Care Medicine organized the International Multidisciplinary Consensus Conference on Multimodality Monitoring..$^{32}$ Results of the meeting provided several important recommendations (e.g., continuous monitoring for ICP in poor-grade aSAH patients) based on a rigorous systematic review, in an effort to unify ICP monitoring strategies among high-volume tertiary centers.

\section{Impact of Raised ICP on aSAH Outcomes}

Despite the variation between studies of the type of ICP monitoring used and the precise cut-off values for elevated ICP, patients with high ICP during their hospital course following aSAH have consistently trended toward higher mortality rates and worse functional outcomes. ${ }^{34,51,74} \mathrm{El}$ evated ICP and its etiologies (ICH, IVH, global edema, and so on) have all been found to be independent predictors of death. ${ }^{13,53,62,71}$ While this association has been identified in large retrospective series, the impact of high ICP on aSAH outcomes has not yet been evaluated in large prospective multicenter series. However, a recent systematic review that examined 26 studies focusing on elevated ICP and aSAH outcomes also concluded that higher ICP following aSAH was associated with a higher mortality 
TABLE 1. Recommendations from the Brain Trauma Foundation for TBI-associated raised ICP and the limitations and implications of applying them to aSAH patients

\begin{tabular}{|c|c|}
\hline Recommendation* & Limitations/Considerations in aSAH Patients \\
\hline $\begin{array}{l}\text { "Bifrontal DC is not recommended to improve outcomes in severe } \\
\text { TBI patients with diffuse injury (without mass lesions)" }\end{array}$ & $\begin{array}{l}\text { Diffuse injury/edema (without mass lesions) occurs in less than } 10 \% \text { of aSAH } \\
\text { patients and is not a common indication for DC in aSAH }\end{array}$ \\
\hline $\begin{array}{l}\text { "Mannitol is effective for control of raised ICP at doses of } 0.25 \text { to } \\
1 \mathrm{~g} / \mathrm{kg} \text { body weight" }\end{array}$ & $\begin{array}{l}\text { Mannitol can lead to serious hypotension and hypovolemia that is against the } \\
\text { recommendation of aSAH guidelines. }{ }^{52,67} \text { Hypertonic saline could be superior to } \\
\text { mannitol since most aSAH patients are hyponatremic }\end{array}$ \\
\hline $\begin{array}{l}\text { "An EVD system zeroed at the midbrain with continuous drainage } \\
\text { of CSF may be considered to lower ICP burden more effec- } \\
\text { tively than intermittent use" }\end{array}$ & $\begin{array}{l}\text { Continuous drainage has been shown to be associated with worse adverse events } \\
\text { in } \mathrm{aSAH}^{57}\end{array}$ \\
\hline $\begin{array}{l}\text { "High-dose barbiturate administration is recommended to control } \\
\text { elevated ICP refractory to maximum standard medical and } \\
\text { surgical treatment" }\end{array}$ & High-dose barbiturate will interfere with neurological monitoring for $\mathrm{DCl}{ }^{20}$ \\
\hline $\begin{array}{l}\text { "The use of steroids is not recommended for improving outcome } \\
\text { or reducing ICP" }\end{array}$ & $\begin{array}{l}\text { Recent studies have linked corticosteroids in SAH patients with favorable out- } \\
\text { comes, }{ }^{17,23,28,37} \text { but it has not been evaluated for aSAH patients with raised ICP }\end{array}$ \\
\hline
\end{tabular}

rate..$^{15}$ Interestingly, this review also found that specific ICP parameters, such as the waveform amplitude, were more predictive of functional outcome than the absolute ICP value. Unfortunately, due to the heterogeneity in the available literature, the authors could not perform a metaanalysis to provide this finding with statistical support.

\section{Management of Raised ICP in aSAH General Principles}

There are no specific guidelines from the American Heart Association ${ }^{14}$ or the Neurocritical Care Society ${ }^{20}$ dedicated to the management of high ICP in patients with aSAH. Most reviews and recommendations are based on TBI guidelines by the Brain Trauma Foundation, which recommend ICP monitoring in those with Glasgow Coma Scale scores $\leq 8$ to maintain ICP $<22 \mathrm{~mm} \mathrm{Hg}$ and cerebral perfusion pressure (CPP) between $60-70$ mm Hg. ${ }^{10}$ Applying the same management algorithm to aSAH has gained traction without any strong supporting evidence of efficacy. Table 1 presents some of the current Brain Trauma Foundation recommendations for elevated ICP and several theoretical limitations to consider when applying them to aSAH.

The initial management of aSAH is highly dependent on initial neuroimaging. ${ }^{20}$ If signs of acute hydrocephalus are present, urgent EVD insertion is a potentially life-saving procedure. The clinical response to EVDs in patients with initially poor neurological status has been shown to be a good predictor of outcome. ${ }^{60}$ However, the ideal rate and duration of CSF drainage following EVD insertion is controversial. A recent randomized controlled trial (RCT) compared continuous CSF drainage to intermittent drainage in 60 patients following aSAH. The investigators found that the overall rate of complications (EVD blockage, infection, CSF leak, hemorrhage) was higher in the continuous drainage group, but there were no significant differences in ICP control, rates of delayed cerebral ischemia (DCI), or functional outcomes. ${ }^{57}$ The optimal dura- tion of CSF diversion, and the techniques for EVD weaning, were not explored in this study and remain the target of future investigation.

\section{Hyperosmolar Agents}

The use of osmotically active agents, such as mannitol and hypertonic saline, to manage elevated ICP is common practice in the setting of trauma and aSAH. Hyperosmolar agents create a gradient across the blood-brain barrier, causing a shift in fluid from the interstitial and intracellular space into the bloodstream. ${ }^{68}$ This decreases the overall fluid volume within the brain and, through the principles of the Monro-Kellie hypothesis, results in a decrease in ICP.

Important differences between mannitol and hypertonic saline exist. Mannitol is a strong diuretic that can cause intravascular volume contraction and alter blood rheology. ${ }^{68}$ Hypertonic saline has minimal diuretic effect and can increase blood pressure and serum sodium. In the setting of aSAH, parameters such as fluid balance, blood pressure, serum sodium, and serum osmolality must be managed carefully to prevent secondary injury and reduce the risk of vasospasm/DCI. ${ }^{18}$ Furthermore, current guidelines recommend euvolemia and hypertensive therapy in the setting of DCI. ${ }^{14}$

The optimal hyperosmolar agent to lower raised ICP in aSAH is contentious. A recent publication surveyed members of the Neurocritical Care Society and found that while $90 \%$ of members used hyperosmolar agents for refractory elevated ICP, $55 \%$ preferred hypertonic saline to mannitol. ${ }^{31}$ Our recent systematic review ${ }^{59}$ on hyperosmolar agents in aSAH revealed 2 randomized studies examining the effect of hypertonic saline on ICP in aSAH. Huang and Yang ${ }^{39}$ found no difference between mannitol and hypertonic saline in controlling refractory raised ICP $\geq 20 \mathrm{~mm} \mathrm{Hg}$. Hypertonic saline decreased ICP by a mean of $9.9 \mathrm{~mm} \mathrm{Hg}(\mathrm{p}<0.01)$. The population was composed of poor-grade patients. A second study by Bentsen et al. ${ }^{5}$ in 
2006 was a single-blind RCT comparing hypertonic saline to normal saline. The patients were hemodynamically stable, with ICP between 10 and $20 \mathrm{~mm} \mathrm{Hg}$. The study was not conducted on patients with refractory raised ICP, as it would be unethical to give normal saline in this scenario. The authors found that hypertonic saline decreased ICP by $3 \mathrm{~mm} \mathrm{Hg}(\mathrm{p}=0.04)$ compared with normal saline.

There is no consensus within the literature with respect to hypertonic saline dose concentration, volume of infusion, or timing of repeat dosing. The most commonly reported hypertonic saline concentrations were between $3 \%$ and $23.5 \%$. Both concentrations appeared effective at decreasing ICP. Most centers used serum sodium of 155-160 and serum osmolality of $320 \mathrm{mEq}$ as the upper limit for safe repeat dosing. ${ }^{59}$

\section{Hypothermia and Barbiturate Coma}

Experimental animal studies have shown that mild hypothermia may reduce cerebral swelling secondary to aSAH and improve outcomes, although this effect failed to translate to clinical studies in humans. ${ }^{51}$ Hypothermia during aneurysm surgery as a method for neuroprotection did not improve patient outcomes in the Intraoperative Hypothermia for Aneurysm Surgery Trial (also known as IHAST), which included 1001 patients ${ }^{69}$ Furthermore, a large single-center, observational study of $100 \mathrm{aSAH}$ patients with raised ICP and/or refractory vasospasm showed an adverse event rate of 93\% following the use of mild hypothermia ${ }^{66}$ which could explain why targeted hypothermia has not been adopted for clinical practice in aSAH. Although cerebral metabolism and cerebral blood flow are often thought to be coupled and to change in a linear fashion, studies have shown that this relationship may in fact be uncoupled during hypothermia, whereby there may be a disproportionate decrease in cerebral blood flow relative to cerebral metabolism. In addition, carbon dioxide production is decreased in hypothermia. This contributes, in part, to the effect of decreased ICP, but it also may cause cerebral hypoperfusion and increase the affinity of hemoglobin for oxygen, thereby further hindering the delivery of oxygen to brain tissue. On the other hand, fever, which is common after aSAH, is an independent predictor of poor outcome..$^{18}$ Higher temperatures induce an acute-phase reaction that leads to an increased cerebral metabolic distress (e.g., release of excitatory amino acids such as glutamate, creation of free radicals, and elevated lactate/pyruvate ratio). ${ }^{48,54,65}$ Therefore, it appears there must be a middle ground whereby the adverse effects of both temperature extremes can be balanced.

The role of hypothermia in poor-grade aSAH was never evaluated in "pre-hospital arrival" settings or "within the acute period after ictus." This has been shown to be beneficial for post-cardiac arrest patients, ${ }^{38,64}$ and given the similarity between poor-grade aSAH and cardiac arrest patients in terms of pathophysiology for early brain injury (e.g., global transient circulatory arrest, hypoxic ischemic mechanisms), early or ultra-early hypothermia is still a potential treatment to be investigated for poor-grade patients. ${ }^{26}$

Barbiturates are usually one of the last interventions to be considered for treating refractory elevated ICP in
TBI due their relatively high rate of adverse events, which include prolonged sedation, metabolic derangements, respiratory suppression, and cardiovascular events. ${ }^{20}$ Barbiturate coma alone has never been evaluated in a dedicated cohort for elevated ICP associated with aSAH. Most centers have reported their experience with a mixed patient sample of many intracranial pathologies. ${ }^{19,43}$ The main drawback of inducing a barbiturate coma in aSAH patients is the loss of the neurological status for DCI monitoring. Symptomatic DCI will be difficult to recognize even during neurological wake-up because the effects of high-dose barbiturates tend to persist after their cessation due to their long biological half-life.$^{55}$ Therefore, using short-acting paralytic agents in combination with sedation could be superior to inducing a full barbiturate coma in aSAH patients. Table 2 shows the studies that were conducted for hypothermia and barbiturates in aSAH patients and demonstrates the heterogeneity among studies in terms of patient selection, outcome measures, and indications for treatment.

\section{Decompressive Craniectomy}

Decompressive craniectomy is frequently used as a life-saving surgical technique for elevated ICP or mass effect secondary to ischemic infarction or TBI. ${ }^{36}$ Multiple studies have found that decompressive craniectomy is very effective in reducing ICP and increasing CPP. However, the effects of decompressive craniectomy on functional outcomes are still controversial. ${ }^{45}$ In the aSAH population, decompressive craniectomy is usually performed to treat poor-grade patients with associated ICH or cerebral infarction and significant mass effect, although these indications are highly variable and are not well studied in the literature. ${ }^{51}$ Our recent meta-analysis ${ }^{1}$ of previous studies examining decompressive craniectomy in patients with poor-grade aSAH showed high pooled event rates of poor outcomes $(60 \%)$ (defined as severe disability, vegetative state, or death) and mortality (29\%) among craniectomy patients; these are not different from the natural history reported for poor-grade patients. ${ }^{6,8}$ This raises concerns about the current practice and indications for decompressive craniectomy in aSAH.

Our meta-analysis results must be carefully interpreted since the quality of evidence is based on observational studies and considered "low-quality" as per the Grading of Recommendations Assessment, Development and Evaluation (GRADE) system for grading clinical evidence. ${ }^{30}$ Furthermore, we were unable to conclude if decompressive craniectomy is superior to medical management for high ICP because a control group was absent in most studies. RCTs are the gold standard in this setting, and there is no doubt that carrying out an RCT of decompressive craniectomy in poor-grade aSAH presents challenges greater than the already known limitations of doing such trials in the overall aSAH population. These new challenges will be related to the heterogeneity of high ICP in aSAH-i.e., the timing, pathology, and severity/cutoff values of high ICP and other factors that may influence imbalances between baseline characteristics, which include clinical herniation signs, ICH volume, and degree of midline shift. Furthermore, the body of evidence on all preoperative 
TABLE 2. Studies with more than 10 patients that were conducted for hypothermia and barbiturates in aSAH

\begin{tabular}{|c|c|c|c|c|c|c|}
\hline Authors \& Year & Country & $\begin{array}{l}\text { No. of } \\
\text { Patients }\end{array}$ & Score & Study Design & Primary Indication & $\begin{array}{l}\text { Outcome } \\
\text { Measures }\end{array}$ \\
\hline \multicolumn{7}{|l|}{ Hypothermia } \\
\hline Hindman et al., 1999 & United States & 52 & WFNS I-III & Randomized trial (pilot) & Neuroprotection during aneurysm surgery & NIHSS \\
\hline Kimme et al., 2004 & Sweden & 266 & $\mathrm{H} \& \mathrm{H} I-\mathrm{V}$ & Prospective & Neuroprotection during aneurysm surgery & Adverse events \\
\hline Todd et al., 2005 & United States & 1001 & WFNS I-III & Randomized trial & Neuroprotection during aneurysm surgery & $\begin{array}{l}\text { GOS, mRS, } \\
\text { Barthel In- } \\
\text { dex, NIHSS }\end{array}$ \\
\hline Chouhan et al., 2006 & India & 47 & WFNS I-V & Randomized trial (pilot) & Neuroprotection during aneurysm surgery & GOS \\
\hline Anei et al., 2010 & Japan & 19 & WFNS IV-V & Retrospective & Neuroprotection for poor-grade aSAH & $\mathrm{mRS}$ \\
\hline \multicolumn{7}{|l|}{$\begin{array}{l}\text { Hypothermia \& barbi- } \\
\text { turates }\end{array}$} \\
\hline Keller et al., 2005 & Switzerland & 23 & $\mathrm{H} \& \mathrm{HI}-\mathrm{V}$ & Prospective & Refractory vasospasm & GOS \\
\hline Seule et al., 2009 & Switzerland & 100 & $\mathrm{H} \& \mathrm{H} I \mathrm{II}-\mathrm{V}$ & Prospective & Raised ICP \&/or refractory vasospasm & $\begin{array}{l}\text { GOS, adverse } \\
\text { events }\end{array}$ \\
\hline \multicolumn{7}{|l|}{ Barbiturates } \\
\hline Finfer et al., 1999 & Australia & 11 & NA & Retrospective & Refractory vasospasm & GOS \\
\hline Dereeper et al., 2002 & Belgium & 21 & $\begin{array}{r}\text { WFNS IV } \\
\text { (mean) }\end{array}$ & Retrospective & Raised ICP & GOS \\
\hline Heo et al., 2003 & Korea & 18 & GCS 4-8 & Prospective & Refractory vasospasm & GCS, GOS \\
\hline
\end{tabular}

GCS = Glasgow Coma Scale; GOS = Glasgow Outcome Scale; H\&H = Hunt and Hess; mRS = modified Rankin Scale; NA = not available; NIHSS = National Institutes of Health Stroke Scale; WFNS = World Federation of Neurosurgical Societies.

management options for high ICP in aSAH is limited, and several important questions need to be answered prior to conducting RCT for decompressive craniectomy in poorgrade aSAH.

\section{Discussion}

Intracranial hypertension is a well-recognized phenomenon in aSAH that has been demonstrated to lead to poor outcomes. ${ }^{18}$ In fact, elevated ICP is known to be a significant contributor to secondary brain injury following aneurysm rupture and is an independent predictor of poor functional outcome and increased mortality. ${ }^{51,74}$ In addition, surgical securing of ruptured aneurysms has been shown to be more complicated when cerebral edema is present. ${ }^{4}$ However, elevated ICP has also long been thought to play a role in the arrest of the hemorrhage such that lowering the ICP may contribute to a greater risk of rebleeding. ${ }^{56}$ There is the notion that a "sweet spot" exists within a certain range of ICP values that will decrease the risk of secondary brain injury and lead to improved outcomes. Several studies on ICP monitoring in TBI have shown that increased monitoring and subsequent control of elevated ICP leads to better outcomes. ${ }^{9,46}$ These same principles have been translated to patients with aSAH despite significant differences in the pathophysiology of the conditions and without the same type of supporting evidence. The relative paucity of well-designed, large-scale randomized trials evaluating the optimal management of elevated ICP following aSAH has led to a lack of consensus to guide clinical management, even for strategies that have been shown be potentially beneficial such as hyperosmolar therapy and decompressive craniectomy. ${ }^{51}$
Some of the complexity of designing studies for intracranial hypertension arise from the ethical obligation to not withhold potentially beneficial treatment from patients. For example, it would be unethical to use a placebo control group for patients with refractory intracranial hypertension. Therefore, in some instances, efforts to resolve the uncertainties in the management of elevated ICP in aSAH may benefit from the utilization of formal consensus methods. That is, using a group of experts in the field to determine agreement or disagreement on various practices. Consensus methods have been shown to be beneficial in instances where published data are scarce and where a wider and more heterogeneous range of information must be taken into consideration. ${ }^{41}$ In the past, consensus methods have been used to resolve a number of critical medical issues, including intraocular lens implantation, coronary artery bypass surgery, and breast cancer treatment. ${ }^{25}$ They are still currently used when there is a lack of published data and/or there are contradictory studies which obfuscate proper interpretation of the available data. In 2016, the World Health Organization used a 3-day consensus conference involving experts from around the world to develop a set of new classification guidelines on central nervous system tumors that was a dramatic change from its 2007 counterpart. ${ }^{49}$ Similarly, the management of aSAH, particularly its complications, which include elevated ICP, can benefit from the same type of consensus method, whereby the effectiveness of various modalities that decrease ICP can be systematically evaluated by a number of different individuals through either the Delphi process, the nominal group technique, or the aforementioned consensus development conference. ${ }^{41}$ 
Our review highlights many unanswered questions for the management of high ICP in aSAH, which require consensus methods and further research. These include the following: establishing ICP/CPP-targeted goals during initial resuscitation, determining optimum methods of CSF drainage and ICP recordings from EVDs, comparing hypertonic saline and mannitol as first-line therapies, examining the role of ultra-early or early hypothermia in poor-grade aSAH, identifying a subgroup that benefits from decompressive craniectomy in terms of functional outcomes, and, most importantly, developing a universal management algorithm that consider the unique hemodynamics and complications of aSAH.

In addition, whenever possible, future prospective trials should still be sought out. In their 2013 review on managing intracranial hypertension in aSAH, Mak et al. supported a future RCT involving decompressive craniectomy for medically refractory intracranial hypertension in aSAH. ${ }^{40,51}$ Matched case-control studies can be performed when randomized studies are not feasible to potentially identify whether ICP monitoring or strict ICP control leads to better functional outcomes in patients presenting with various grades of hemorrhages. Lastly, because the definitions of "normal" and "elevated" ICP in aSAH have traditionally been translated directly from studies on TBI, they may need to be adjusted considering the significant differences in pathophysiology. For example, a higher range of ICP levels may be more permissible in aSAH due to its hemostatic effect on preventing rebleeding compared with that in TBI and also because most aSAH patients presents with a high mean arterial blood pressure, which may allow for cerebral hyperperfusion to develop if ICP is rapidly lowered. However, currently no studies have been able to describe a well-defined and reliable range of what constitutes physiological and pathological ICP in aSAH. Identifying time-dependent ICP thresholds for aSAH patients may have important implications for guiding targeted therapy and predicting outcomes. ${ }^{63}$

\section{Conclusions}

The roles of all current management interventions to treat high ICP in aSAH are not well studied. Accordingly, there is an urgent need to examine the best available evidence with systematic reviews and establish consensus methods. This will have important implications for designing future studies and developing standardized management protocols.

\section{Acknowledgments}

Dr. Macdonald receives grant support from the Brain Aneurysm Foundation, Canadian Institutes for Health Research, and the Heart and Stroke Foundation of Canada. Dr. Saposnik is supported by the 2017-2021 Heart and Stroke Foundation of Canada Mid-Career Scientist Award.

\section{References}

1. Alotaibi NM, Elkarim GA, Samuel N, Ayling OGS, Guha D, Fallah A, et al: Effects of decompressive craniectomy on functional outcomes and death in poor-grade aneurysmal subarachnoid hemorrhage: a systematic review and metaanalysis. J Neurosurg [epub ahead of print January 6, 2017. DOI: 10.3171/2016.9.JNS161383]

2. Alotaibi NM, Nassiri F, Badhiwala JH, Witiw CD, Ibrahim GM, Macdonald RL, et al: The most cited works in aneurysmal subarachnoid hemorrhage: a bibliometric analysis of the 100 most cited articles. World Neurosurg 89:587-592, 592. e1-592.e6, 2016

3. Anei R, Sakai H, Iihara K, Nagata I: Effectiveness of brain hypothermia treatment in patients with severe subarachnoid hemorrhage: comparisons at a single facility. Neurol Med Chir (Tokyo) 50:879-883, 2010

4. Bailes JE, Spetzler RF, Hadley MN, Baldwin HZ: Management morbidity and mortality of poor-grade aneurysm patients. J Neurosurg 72:559-566, 1990

5. Bentsen G, Breivik H, Lundar T, Stubhaug A: Hypertonic saline $(7.2 \%)$ in $6 \%$ hydroxyethyl starch reduces intracranial pressure and improves hemodynamics in a placebocontrolled study involving stable patients with subarachnoid hemorrhage. Crit Care Med 34:2912-2917, 2006

6. Bing Z, Rabinstein AA, Murad MH, Lanzino G, Panni P, Brinjikji W: Surgical and endovascular treatment of poorgrade aneurysmal subarachnoid hemorrhage: a systematic review and meta-analysis. J Neurosurg Sci 61:403-415, 2017

7. Bor-Seng-Shu E, Figueiredo EG, Amorim RL, Teixeira MJ, Valbuza JS, de Oliveira MM, et al: Decompressive craniectomy: a meta-analysis of influences on intracranial pressure and cerebral perfusion pressure in the treatment of traumatic brain injury. J Neurosurg 117:589-596, 2012

8. Bracard S, Lebedinsky A, Anxionnat R, Neto JM, Audibert G, Long Y, et al: Endovascular treatment of Hunt and Hess grade IV and V aneuryms. AJNR Am J Neuroradiol 23:953-957, 2002

9. Bulger EM, Nathens AB, Rivara FP, Moore M, MacKenzie EJ, Jurkovich GJ: Management of severe head injury: institutional variations in care and effect on outcome. Crit Care Med 30:1870-1876, 2002

10. Carney N, Totten AM, O'Reilly C, Ullman JS, Hawryluk GW, Bell MJ, et al: Guidelines for the management of severe traumatic brain injury, fourth edition. Neurosurgery 80:615,2017

11. Chen H, Wang J, Mao S, Dong W, Yang H: A new method of intracranial pressure monitoring by EEG power spectrum analysis. Can J Neurol Sci 39:483-487, 2012

12. Chouhan R, Dash H, Bithal P, Chaturvedi A, Pandia M, Radhakrishnan M, et al: Intraoperative mild hypothermia for brain protection during intracranial aneurysm surgery. J Anaesthesiol Clin Pharmacol 22:21-28, 2006

13. Claassen J, Carhuapoma JR, Kreiter KT, Du EY, Connolly ES, Mayer SA: Global cerebral edema after subarachnoid hemorrhage: frequency, predictors, and impact on outcome. Stroke 33:1225-1232, 2002

14. Connolly ES Jr, Rabinstein AA, Carhuapoma JR, Derdeyn CP, Dion J, Higashida RT, et al: Guidelines for the management of aneurysmal subarachnoid hemorrhage: a guideline for healthcare professionals from the American Heart Association/American Stroke Association. Stroke 43:1711-1737, 2012

15. Cossu G, Messerer M, Stocchetti N, Levivier M, Daniel RT, Oddo M: Intracranial pressure and outcome in critically ill patients with aneurysmal subarachnoid hemorrhage: a systematic review. Minerva Anestesiol 82:684-696, 2016

16. Cross DT III, Moran CJ, Angtuaco EE, Milburn JM, Diringer MN, Dacey RG Jr: Intracranial pressure monitoring during intraarterial papaverine infusion for cerebral vasospasm. AJNR Am J Neuroradiol 19:1319-1323, 1998

17. Czorlich P, Sauvigny T, Ricklefs F, Abboud T, Nierhaus A, Vettorazzi E, et al: Impact of dexamethasone in patients 
with aneurysmal subarachnoid haemorrhage. Eur J Neurol 24:645-651, 2017

18. de Oliveira Manoel AL, Goffi A, Marotta TR, Schweizer TA, Abrahamson S, Macdonald RL: The critical care management of poor-grade subarachnoid haemorrhage. Crit Care 20:21, 2016

19. Dereeper E, Berré J, Vandesteene A, Lefranc F, Vincent JL: Barbiturate coma for intracranial hypertension: clinical observations. J Crit Care 17:58-62, 2002

20. Diringer MN, Bleck TP, Claude Hemphill J III, Menon D, Shutter L, Vespa P, et al: Critical care management of patients following aneurysmal subarachnoid hemorrhage: recommendations from the Neurocritical Care Society's Multidisciplinary Consensus Conference. Neurocrit Care 15:211-240, 2011

21. D'Souza S: Aneurysmal Subarachnoid Hemorrhage. J Neurosurg Anesthesiol 27:222-240, 2015

22. Etminan N, Macdonald RL: Management of aneurysmal subarachnoid hemorrhage. Handb Clin Neurol 140:195-228, 2017

23. Fei L, Golwa F: Topical application of dexamethasone to prevent cerebral vasospasm after aneurysmal subarachnoid haemorrhage: a pilot study. Clin Drug Investig 27:827-832, 2007

24. Finfer SR, Ferch R, Morgan MK: Barbiturate coma for severe, refractory vasospasm following subarachnoid haemorrhage. Intensive Care Med 25:406-409, 1999

25. Fink A, Kosecoff J, Chassin M, Brook RH: Consensus methods: characteristics and guidelines for use. Am J Public Health 74:979-983, 1984

26. Frontera JA: Clinical trials in cardiac arrest and subarachnoid hemorrhage: lessons from the past and ideas for the future. Stroke Res Treat 2013:263974, 2013

27. Gigante P, Hwang BY, Appelboom G, Kellner CP, Kellner MA, Connolly ES: External ventricular drainage following aneurysmal subarachnoid haemorrhage. Br J Neurosurg 24:625-632, 2010

28. Gomis P, Graftieaux JP, Sercombe R, Hettler D, Scherpereel B, Rousseaux P: Randomized, double-blind, placebo-controlled, pilot trial of high-dose methylprednisolone in aneurysmal subarachnoid hemorrhage. J Neurosurg 112:681688,2010

29. Güresir E, Schuss P, Vatter H, Raabe A, Seifert V, Beck J: Decompressive craniectomy in subarachnoid hemorrhage. Neurosurg Focus 26(6):E4, 2009

30. Guyatt GH, Oxman AD, Vist GE, Kunz R, Falck-Ytter Y, Alonso-Coello P, et al: GRADE: an emerging consensus on rating quality of evidence and strength of recommendations. BMJ 336:924-926, 2008

31. Hays AN, Lazaridis C, Neyens R, Nicholas J, Gay S, Chalela JA: Osmotherapy: use among neurointensivists. Neurocrit Care 14:222-228, 2011

32. Helbok R, Olson DM, Le Roux PD, Vespa P: Intracranial pressure and cerebral perfusion pressure monitoring in nonTBI patients: special considerations. Neurocrit Care 21 (Suppl 2):S85-S94, 2014

33. Heo DH, Hu C, Cho SM, Whang K, Pyen JS, Kim HJ: Barbiturate coma therapy in severe and refractory vasospasm following subarachnoid hemorrhage. J Korean Neurosurg Soc 33:142-148, 2003

34. Heuer GG, Smith MJ, Elliott JP, Winn HR, LeRoux PD: Relationship between intracranial pressure and other clinical variables in patients with aneurysmal subarachnoid hemorrhage. J Neurosurg 101:408-416, 2004

35. Hindman BJ, Todd MM, Gelb AW, Loftus CM, Craen RA, Schubert A, et al: Mild hypothermia as a protective therapy during intracranial aneurysm surgery: a randomized prospective pilot trial. Neurosurgery 44:23-33, 1999

36. Hofmeijer J, Kappelle LJ, Algra A, Amelink GJ, van Gijn J, van der Worp HB: Surgical decompression for space-occupying cerebral infarction (the Hemicraniectomy After Middle Cerebral Artery infarction with Life-threatening Edema Trial [HAMLET]): a multicentre, open, randomised trial. Lancet Neurol 8:326-333, 2009

37. Höllig A, Thiel M, Stoffel-Wagner B, Coburn M, Clusmann $\mathrm{H}$ : Neuroprotective properties of dehydroepiandrosteronesulfate and its relationship to interleukin 6 after aneurysmal subarachnoid hemorrhage: a prospective cohort study. Crit Care 19:231, 2015

38. Holzer M, Cerchiari E, Martens P, Roine R, Sterz F, Eisenburger P, et al: Mild therapeutic hypothermia to improve the neurologic outcome after cardiac arrest. N Engl J Med 346:549-556, 2002 (Erratum in N Engl J Med 346:1756, 2002)

39. Huang XC, Yang LL: [Comparison clinical efficacy of $3 \%$ hypertonic saline solution with $20 \%$ mannitol in treatment of intracranial hypertension in patients with aneurysmal subarachnoid hemorrhage.] Zhejiang Da Xue Xue Bao Yi Xue Ban 44:389-395, 2015 (Chinese)

40. Hutchinson PJ, Kolias AG, Timofeev IS, Corteen EA, Czosnyka M, Timothy J, et al: Trial of decompressive craniectomy for traumatic intracranial hypertension. N Engl J Med 375:1119-1130, 2016

41. Jones J, Hunter D: Consensus methods for medical and health services research. BMJ 311:376-380, 1995

42. Keller E, Krayenbühl N, Bjeljac M, Yonekawa Y: Cerebral vasospasm: results of a structured multimodal treatment. Acta Neurochir Suppl 94:65-73, 2005

43. Kim YI, Park SW, Nam TK, Park YS, Min BK, Hwang SN: The effect of barbiturate coma therapy for the patients with severe intracranial hypertension: a 10-year experience. J Korean Neurosurg Soc 44:141-145, 2008

44. Kimme P, Fridrikssen S, Engdahl O, Hillman J, Vegfors M, Sjöberg F: Moderate hypothermia for 359 operations to clip cerebral aneurysms. Br J Anaesth 93:343-347, 2004

45. Kolias AG, Kirkpatrick PJ, Hutchinson PJ: Decompressive craniectomy: past, present and future. Nat Rev Neurol 9:405-415, 2013

46. Lane PL, Skoretz TG, Doig G, Girotti MJ: Intracranial pressure monitoring and outcomes after traumatic brain injury. Can J Surg 43:442-448, 2000

47. Lantigua H, Ortega-Gutierrez S, Schmidt JM, Lee K, Badjatia N, Agarwal S, et al: Subarachnoid hemorrhage: who dies, and why? Crit Care 19:309, 2015

48. Li LR, You C, Chaudhary B: Intraoperative mild hypothermia for postoperative neurological deficits in intracranial aneurysm patients. Cochrane Database Syst Rev (2):CD008445, 2012

49. Louis DN, Perry A, Reifenberger G, von Deimling A, Figarella-Branger D, Cavenee WK, et al: The 2016 World Health Organization classification of tumors of the central nervous system: a summary. Acta Neuropathol 131:803-820, 2016

50. Macdonald RL, Schweizer TA: Spontaneous subarachnoid haemorrhage. Lancet 389:655-666, 2017

51. Mak CH, Lu YY, Wong GK: Review and recommendations on management of refractory raised intracranial pressure in aneurysmal subarachnoid hemorrhage. Vasc Health Risk Manag 9:353-359, 2013

52. Marko NF: Hypertonic saline, not mannitol, should be considered gold-standard medical therapy for intracranial hypertension. Crit Care 16:113-113, 2012

53. Mocco J, Prickett CS, Komotar RJ, Connolly ES, Mayer SA: Potential mechanisms and clinical significance of global cerebral edema following aneurysmal subarachnoid hemorrhage. Neurosurg Focus 22(5):E7, 2007

54. Mrozek S, Vardon F, Geeraerts T: Brain temperature: physiology and pathophysiology after brain injury. Anesthesiol Res Pract 2012:989487, 2012 
55. Nelson E, Powell JR, Conrad K, Likes K, Byers J, Baker S, et al: Phenobarbital pharmacokinetics and bioavailability in adults. J Clin Pharmacol 22:141-148, 1982

56. Nornes H: The role of intracranial pressure in the arrest of hemorrhage in patients with ruptured intracranial aneurysm. J Neurosurg 39:226-234, 1973

57. Olson DM, Zomorodi M, Britz GW, Zomorodi AR, Amato A, Graffagnino C: Continuous cerebral spinal fluid drainage associated with complications in patients admitted with subarachnoid hemorrhage. J Neurosurg 119:974-980, 2013

58. Otani N, Takasato Y, Masaoka H, Hayakawa T, Yoshino Y, Yatsushige $\mathrm{H}$, et al: Clinical characteristics and surgical outcomes of patients with aneurysmal subarachnoid hemorrhage and acute subdural hematoma undergoing decompressive craniectomy. World Neurosurg 75:73-77, 2011

59. Pasarikovski CR, Alotaibi NM, Al-Mufti F, Macdonald RL: Hypertonic saline for raised intracranial pressure following aneurysmal subarachnoid hemorrhage: a systematic review. World Neurosurg 105:1-6, 2017

60. Ransom ER, Mocco J, Komotar RJ, Sahni D, Chang J, Hahn DK, et al: External ventricular drainage response in poor grade aneurysmal subarachnoid hemorrhage: effect on preoperative grading and prognosis. Neurocrit Care 6:174-180, 2007

61. Rogers M, Stutzman SE, Atem FD, Sengupta S, Welch B, Olson DM: Intracranial pressure values are highly variable after cerebral spinal fluid drainage. J Neurosci Nurs 49:85-89, 2017

62. Rosengart AJ, Schultheiss KE, Tolentino J, Macdonald RL: Prognostic factors for outcome in patients with aneurysmal subarachnoid hemorrhage. Stroke 38:2315-2321, 2007

63. Sauvigny T, Göttsche J, Czorlich P, Vettorazzi E, Westphal $\mathrm{M}$, Regelsberger J: Intracranial pressure in patients undergoing decompressive craniectomy: new perspective on thresholds. J Neurosurg [epub ahead of print April 14, 2017. DOI: 10.3171/2016.11.JNS162263]

64. Scirica BM: Therapeutic hypothermia after cardiac arrest. Circulation 127:244-250, 2013

65. Seule MA, Muroi C, Mink S, Yonekawa Y, Keller E: Therapeutic hypothermia in patients with aneurysmal subarachnoid hemorrhage, refractory intracranial hypertension, or cerebral vasospasm. Neurosurgery 64:86-93, 2009

66. Springborg JB, Frederiksen HJ, Eskesen V, Olsen NV: Trends in monitoring patients with aneurysmal subarachnoid haemorrhage. Br J Anaesth 94:259-270, 2005

67. Strandvik GF: Hypertonic saline in critical care: a review of the literature and guidelines for use in hypotensive states and raised intracranial pressure. Anaesthesia 64:990-1003, 2009

68. Thongrong C, Kong N, Govindarajan B, Allen D, Mendel E,
Bergese SD: Current purpose and practice of hypertonic saline in neurosurgery: a review of the literature. World Neurosurg 82:1307-1318, 2014

69. Todd MM, Hindman BJ, Clarke WR, Torner JC: Mild intraoperative hypothermia during surgery for intracranial aneurysm. N Engl J Med 352:135-145, 2005

70. Tuzgen S, Kucukyuruk B, Aydin S, Ozlen F, Kizilkilic O, Abuzayed B: Decompressive craniectomy in patients with cerebral infarction due to malignant vasospasm after aneurysmal subarachnoid hemorrhage. J Neurosci Rural Pract 3:251-255, 2012

71. Wan A, Jaja BN, Schweizer TA, Macdonald RL: Clinical characteristics and outcome of aneurysmal subarachnoid hemorrhage with intracerebral hematoma. J Neurosurg 125:1344-1351, 2016

72. Wartenberg KE, Schmidt JM, Claassen J, Temes RE, Frontera JA, Ostapkovich N, et al: Impact of medical complications on outcome after subarachnoid hemorrhage. Crit Care Med 34:617-624, 2006

73. Weerakkody RA, Czosnyka M, Zweifel C, Castellani G, Smielewski P, Keong N, et al: Slow vasogenic fluctuations of intracranial pressure and cerebral near infrared spectroscopy - an observational study. Acta Neurochir (Wien) 152:1763-1769, 2010

74. Zoerle T, Lombardo A, Colombo A, Longhi L, Zanier ER, Rampini $P$, et al: Intracranial pressure after subarachnoid hemorrhage. Crit Care Med 43:168-176, 2015

\section{Disclosures}

Dr. Macdonald reports that he is an employee and the Chief Scientific Officer of Edge Therapeutics, Inc.

\section{Author Contributions}

Conception and design: Alotaibi. Acquisition of data: Alotaibi, Wang, Pasarikovski. Analysis and interpretation of data: all authors. Drafting the article: Alotaibi, Wang, Pasarikovski, Guha. Critically revising the article: all authors. Reviewed submitted version of manuscript: all authors. Approved the final version of the manuscript on behalf of all authors: Alotaibi. Study supervision: Alotaibi, Macdonald.

\section{Correspondence}

Naif M. Alotaibi, Division of Neurosurgery, University of Toronto, 399 Bathurst St., WW 4-427, Toronto, ON M5T 2S8, Canada. email: naif.alotaibi@mail.utoronto.ca. 